\title{
VALUASI EKONOMI HUTAN MANGROVE DI TANJUNG DUDEPO, KECAMATAN BOLAANG UKI, KABUPATEN BOLAANG MONGONDOW SELATAN
}

\author{
Rey Wahyudi Simbala \\ Hengki Djemie Walangitan \\ Charles Kepel
}

\begin{abstract}
The objectives of the study were to analyze: (1) direct and indirect benefits; and (2) The total economic value of mangrove forests in Dudepo Cape, Bolaang Uki Sub-district, South Bolaang Mongondow Regency, North Sulawesi Province. This research was conducted inside and around the area of mangrove protected forest in Dudepo Cape. The study was conducted for 3 (three) months from January - March of 2016. This research uses primary data and secondary data. Primary data were collected through interviews with the community based on prepared questionnaires. Sampling colection using purposive sampling method. Secondary data were collected including from Bolaang Uki Subdistrict Office and Dudepo Village Office. The data collected from the field were analyzed using descriptive and quantitative analysis methods. The study found that (1) the direct benefits earned by the community consisted of the value of forest products and the value of the fishery benefits (the benefits of wood for house construction, the benefits of wood for houses, the benefits of firewood, the benefits of wood for stakes and fences, the benefits of shrimp, and the benefits of crabs). While the value of indirect benefits of abrasion retention and erosion benefits, the benefits of choice, the benefits of existence and inheritance benefits. (2) The total economic value of mangrove forest ecosystem in Dudepo village consists of direct benefit value of Rp. 822,165,000 / year of indirect benefit amount of Rp. 453.792.178 / year, the value of the preferred benefit of Rp. 306.405.000./year, the value of the existence benefit of Rp. 1.372.635 / year, the value of the existence benefit of Rp. 13.353 .660 / year. and inheritance value of Rp. 82.216.500 / year. The total economic value of the total benefit of mangrove forest ecosystem in Dudepo village is $R p$. 1.677.932.338./ year.
\end{abstract}

Keywords: economic value, mangrove forest ecosystem, Dudepo Cape, South Bolaang Mongondow County District

ABSTRAK
Tujuan penelitian adalah menganalisis: (1) Manfaat langsung dan tidak langsung; dan (2) Nilai ekonomi total dari hutan mangrove di Tanjung Dudepo, Kecamatan Bolaang Uki, Kabupaten Bolaang Mongondow Selatan, Provinsi Sulawesi Utara. Penelitian ini dilakukan di dalam dan di sekitar kawasan hutan lindung mangrove di Tanjung Dudepo. Penelitian dilaksanakan selama 3 (tiga) bulan terhitung dari bulan Januari - Maret Tahun 2016. Penelitian ini menggunakan data primer dan data sekunder. Data primer dikumpulkan melalui wawancara dengan masyarakat berdasarkan kuesioner yang telah disiapkan. Pengambilan sampel menggunakan metode purposive sampling. Data sekunder dikumpulkan, antara lain, dari Kantor Kecamatan Bolaang Uki dan Kantor Desa Dudepo. Data-data yang dikumpulkan dari lapangan dianalisis dengan menggunakan metode analisis deskriptif dan kuantitatif. Penelitian ini menemukan bahwa (1) nilai manfaat langsung yang didapatkan oleh masyarakat terdiri atas nilai manfaat hasil hutan dan nilai manfaat perikanan (manfaat kayu untuk konstruksi rumah, manfaat kayu untuk bangunan rumah, manfaat kayu bakar, manfaat kayu untuk patok dan pagar, manfaat ikan, manfaat udang, dan manfaat kepiting). Sedangkan nilai manfaat tidak langsung manfaat penahan abrasi dan erosi, manfaat pilihan, manfaat eksistensi dan manfaat warisan. (2) Nilai ekonomi total ekosistem hutan mangrove di Desa Dudepo terdiri atas nilai manfaat langsung sebesar Rp. 822.165.000/tahun nilai manfaat tidak langsung sebesar Rp. 453.792.178/tahun, nilai manfaat pilihan sebesar Rp. 306.405.000./tahun, nilai manfaat eksistensi sebesar Rp. 1.372.635/tahun, nilai manfaat eksistensi sebesar Rp. 13.353.660/tahun. dan nilai manfaat warisan sebesar Rp. 82.216.500/tahun. Jumlah nilai ekonomi total keseluruhan manfaat ekosistem hutan mangrove di Desa Dudepo adalah sebesar Rp. 1.677.932.338./tahun.

Kata kunci: nilai ekonomi, ekosistem hutan mangrove, Tanjung Dudepo, Kabupaten Bolaang Mongondow Selatan 


\section{PENDAHULUAN}

\section{Latar Belakang}

Salah satu sumber daya alam yang banyak dimanfaatkan oleh masyarakat khususnya yang berada di wilayah pesisir adalah mangrove. Hutan mangrove merupakan sumberdaya alam khas pesisir tropika, yang mempunyai manfaat ganda dengan pengaruh yang sangat luas apabila ditinjau dari aspek sosial, ekonomi dan ekologi. Sumberdaya alam mempunyai peran penting dalam kelangsungan hidup manusia. Pengelolaan terhadap sumberdaya alam harus sangat bijaksana. Karena diperlukan waktu yang cukup lama untuk bisa memulihkan kembali apabila telah terjadi kerusakan/kepunahan. Besarnya manfaat yang ada pada ekosistem hutan mangrove, memberikan konsekuensi bagi ekosistem hutan mangrove itu sendiri, yaitu dengan semakin tingginya tingkat eksploitasi terhadap lingkungan yang tidak jarang berakhir pada degradasi lingkungan yang cukup parah. Luasan mangrove Tanjung Dodepo Kecamatan Bolaang Uki memiliki ekosistem mangrove terluas (183.950) Hektar dibanding dengan kecamatan lainnya di Kabupaten Bolaang Mongondow Selatan. Sejalan dengan penetapan Molibagu sebagai Ibu Kota Kabupaten Bolaang Mongodow Selatan, peningkatan kegiatan pembangunan fasilitas infrastruktur serta penyebaran penduduk kian pesat. Selain itu adanya beragam kepentingan dalam pemenuhan kebutuhan hidup masyarakat memberikan dampak negatif terhadap kelangsungan hidup ekosistem hutan mangrove dan sumberdaya didalamnya. Salah satu yang menjadi alternatif masyarakat adalah pemanfaatan ekosistem hutan mangrove. Masyarakat pada umumnya cenderung untuk menggantungkan hidupnya pada sumber daya pesisir yang ada disekitar mereka karena lebih mementingkan kemudahan dalam memperolehnya. Dari manfaat yang diperoleh, terdapat nilai ekonomi yang secara langsung dan tidak langsung berdampak pada kehidupan masyarakat setempat. Selain itu, nilai ekonomi yang terkandung dalam ekosistem hutan mangrove sangat berperan penting dalam penentuan kebijakan pengelolaannya, mengingat ekosistem hutan mangrove yang terdapat di Tanjung Dudepo merupakan bagian dari kawasan lindung yang telah dietapkan sejak tahun 1984 oleh Pemerintah lewat Surat Keputusan Menteri Kehutanan, dan kembali dipertegas pada tahun 1999. Namun kenyataannya hingga saat ini tahun 2017, eksploitasi masih saja terjadi sehingga mengakibatkan rusaknya ekosistem mangrove yang ada di Tanjung Dudepo. Dari beberapa permasalahan di atas maka dapat dirumuskan permasalahan yang akan diteliti adalah : Valuasi Ekonomi Sumber Daya Hutan Mangrove di Tanjung Dudepo Kecamatan Bolaang Uki Kabupaten Bolaang Mongondow Selatan. Kerangka nilai ekonomi yang digunakan dalam evaluasi ekonomi sumberdaya alam termasuk mangrove adalah konsep Nilai ekonomi Total (total economic value/TEV) yang secara garis besar terdiri atas dua kelompok yaitu nilai atas dasar penggunaan (use value) dan nilai yang terkandung didalamnya atau nilai intristik (non use value) yang dinilai berdasarkan harga pasar, harga tidak langsung dan metode kontingensi (contingent valuation methodel CVM). Oleh karena itu, valuasi terhadap nilai ekonomi sumberdaya hutan mangrove di Tanjung Dodepo merupakan salah satu cara untuk mengetahui besarnya nilai ekonomi total dari setiap manfaat yang diperoleh. Dengan mengetahui nilai ekonomi total yang diperoleh, nantinya akan berdampak terhadap besarnya penghargaan masyarakat terhadap barang dan jasa yang dihasilkan ekosistem hutan mangrove.

\section{Rumusan Masalah}

Keberadaan ekosistem hutan mangrove di Tanjung Dodepo, telah memberikan manfaat yang besar terhadap masyarakat sekitar dalam menunjang kehidupannya. Namun selama ini, masyarakat tidak mengetahui secara keseluruhan manfaat langsung dan tidak langsung serta seberapa besar nilai yang mereka dapat dari manfaat tersebut. Maka dapat dirumuskan permasalahan yang akan dikaji adalah:

1. Bagaimana manfaat langsung dan tidak langsung hutan mangove di tanjung Dudepo Kecamatan Bolaang Uki Kabupaten Bolaang Mongondow Selatan? 
2. Bagaimana nilai ekonomi total hutan mangrove di tanjung dudepo Kecamatan Bolaang Uki Kabupaten Bolaang Mongondow Selatan?

\section{Tujuan Penelitian}

Tujuan dari penelitian ini adalah :

1. Menganalisis manfaat langsung dan tidak langsung hutan mangove di Tanjung Dudepo Kecamatan Bolaang Uki Kabupaten Bolaang Mongondow Selatan

2. Menganalisis nilai ekonomi total hutan mangrove di tanjung dudepo Kecamatan Bolaang Uki Kabupaten Bolaang Mongondow Selatan

\section{METODOLOGI PENELITIAN}

\section{Tempat dan Waktu Penelitian}

Penelitian mengenai valuasi ekonomi hutan mangrove dilakukan didalam dan disekitar kawasan hutan lindung mangrove di Tanjung Dudepo, serta di Desa Dudepo Kecamatan Bolaang Uki Kabupaten Bolaang Mongondow Selatan, Propinsi Sulawesi Utara. Penelitian dilaksanakan selama 3 (tiga) bulan terhitung dari bulan Januari - Maret Tahun 2016.

\section{Metode Pengumpulan Data}

Metode penelitian yang di gunakan dalam penelitian ini adalah Metode survey atau observasi. Dalam melakukan survey dilakukan pengumpulan data yang dikumpulkan dalam penelitian ini terdiri dari data primer dan data sekunder. Data primer dilakukan dengan wawancara atau kuisioner dengan masyarakat Data primer berupa seluruh informasi yang di peroleh secara langsung di lapangan, di ambil dengan cara mewawancarai dan menyebarkan kuisioner pada masyarakat. Jumlah responden yang di ambil menggunakan metode purposive random sampling, yaitu : penentuan responden secara acak dan setiap responden memiliki kesempatan yang sama di ambil sebagai sampel.

\section{Pengambilan Sampel Mangrove}

Luas populasi hutan mangrove sebagai lokasi tempat penelitian adalah $15 \mathrm{Ha}$ yaitu hutan mangrove yang terletak di Desa Dudepo dan luas yang digunakan sebagai tempat pengambilan sampel adalah 2 Hektar atau $13 \%$ dari luas populasi keseluruhan. Pengambilan sampel mangrove dilakukan dengan rnenggunakan metode stasiun jalur berpetak (Bengen, 2006). Setiap stasiun ditarik garis dan dibuat petak dengan ukuran $20 \mathrm{~m} \mathrm{x} 50 \mathrm{~m}$ sebanyak 20 petak pada setiap stasiun dalam 3 sampel stasiun dan dilakukan secara acak untuk mewakili sampel pada lokasi penelitian. Penarikan garis dilakukan dari garis pantai dpl.

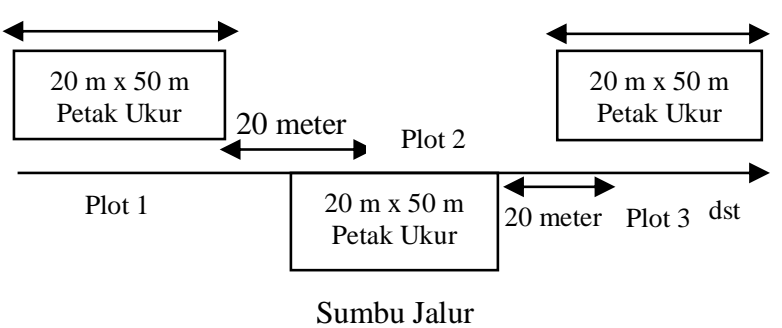

Gambar 1. Sketsa metode penempatan transek dan kuadrat

\section{Variabel Pengamatan}

Variabel yang akan diamati dalam penelitian ini adalah :

1. Nilai manfaat langsung yaitu nilai yang dihasilkan dari pemanfaatan secara langsung hutan mangrove adalah : nilai manfaat yaitu nilai manfaat kayu untuk konstruksi rumah, manfaat kayu untuk bangunan rumah, manfaat kayu bakar, manfaat kayu untuk patok pagar, nilai manfaat ikan, nilai manfaat udang, dan nilai manfaat kepiting. (Rp/tahun).

3. Nilai manfaat tidak langsung yaitu nilai yang dihasilkan dari pemanfaatan secara tidak langsung hutan mangrove: pemecah ombak (break water) (Rp/tahun)

4. Nilai manfaat pilihan yaitu nilai ekonomi yang diperoleh dari potensi pemanfaatan langsung maupun tidak langsung dari sebuah sumber- daya/ekosistem di masa datang: nilai Biodiver- sity (Rp/tahun).

5. Nilai manfaat keberadaan yaitu biaya yang dikeluarkan oleh pemanfaat hutan mangrove untuk mendapatkan komoditi dari hutan mangrove ( $\mathrm{Rp} /$ tahun).

6. Manfaat warisan yaitu ekosistem mangrove dihitung dengan pendekatan perkiraan dengan nilai warisan tidak kurang $10 \%$ dari nilai manfaat langsung hutan mangrove. 
Variabel - variabel ini diidentifikasi dan dikuantifikasikan berdasarkan metode penilaian yang akan didekati seperti harga pasar, harga tidak langsung, metode benefit transfer dan Contingen Valuation Methode (CVM) atau metode survey.

\section{Analisis Data}

Data-data yang diperoleh dari hasil pengamatan di lapangan yaitu mengenai vegetasi dan pemanfaatan hutan mangrove, dianalisis dengan menggunakan metode analisis deskriptif dan kuantitatif. Analisis deskriptif digunakan untuk menjelaskan kondisi hutan mangrove di Desa Dudepo, keadaan dan kondisi sosial ekonomi masyarakat sekitar kawasan hutan mangrove dan pemanfaatan dari hutan mangrove. Sedangkan analisis kuantitatif digunakan untuk mengetahui potensi yang terkandung di kawasan hutan mangrove, nilai manfaat ekonomi dari keberadaan ekosistem hutan mangrove dan pendapat masyarakat akan keberadaan kawasan hutan mangrove. Dalam penelitian ini, Data yang telah didapatkan dari hasil penelitian kemudian dikumpulkan serta diolah dan dianalisis yang disajikan dalam bentuk tabulasi.

\section{HASIL DAN PEMBAHASAN}

\section{Deskripsi Lokasi Penelitian}

Desa Dudepo merupakan salah satu Desa di Kecamatan Bolaang Uki yang secara administratif berada dalam wilayah Kabupaten Bolaang Mongondow Selatan, Provinsi Sulawesi Utara. Desa Dudepo memiliki batasbatas wilayah sebagai berikut : Sebelah Utara berbatasan dengan Hutan Produksi dan TNBNW, Sebelah Selatan berbatasan dengan Teluk Tomini, Sebelah Timur berbatasan dengan Desa Pinolantungan dan Sebelah Barat berbatasan dengan Desa Tangagah. Luas wilayah Desa Dudepo secara keseluruhan adalah 16,10 $\mathrm{KM}^{2}$. Dengan jumlah Penduduk 262 kepala keluarga, sebanyak 1.077 jiwa yang terdiri dari laki-laki 545 jiwa dan Perempuan sebanyak 532 jiwa. Dengan luas wilayah 16,10 $\mathrm{KM}^{2}$ dengan kepadatan Penduduk di Desa Dudepo adalah 67 jiwa/KM² (Anonimous,2010). Hamparan komunitas mangrove sepanjang Tanjung Dudepo tumbuh pada daerah pantai yang topografinya landai, serta tekstur tanahnya yang lebih dominan adalah lumpur berpasir sehingga mangrove cocok tumbuh di tempat ini, khususnya mangrove spesies Rhizophora mucronata, Rizophora apiculata, Ceriops tagal, Bruguiera gymnorhiza, Soneratia alba, dan Avicennia alba walaupun populasinya agak kurang.

\section{Komposi Mangrove}

\section{a. Deskripsi Jenis Mangrove}

Spesies mangrove yang ditemukan di lokasi penelitian sesuai hasil identifikasi dilapangan ada 7 spesies Yaitu :

1. Avicennia alb

2. Bruguiera gymnorrhiza

3. Ceriops tagal

4. Rhizophora apiculata

5. Rhizophora mucronata

6. Sonneratia alba

7. Aegiceras corniculatum

\section{Pola Zonasi ( Sebaran ) Mangrove}

Pada stasiun I zona yang mendominasi adalah asosiasi dari zona Aegiceras corniculatum, kemudian dilanjutkan dengan zona yang merupakan asosiasi dari family Rhizophoraceae (Bruguiera pymnorrhiza, Ceriops tagal, Rhizophora apiculata, Rhizophora mucronata), dan pada zona terakhir merupakan asosiasi antara Avicennia alba dan Sonneratia alba.

Pada stasiun II jenis yang didapati sedikit lebih kurang dari jenis yang ada di stasiun I. Dimana zona pertama didominasi oleh family Rhizophoraceae $(R$ mucronata, $R$ apiculata, Ceriops tagal, bruguiera gymnorhiz) dan selanjutnya adalah zona Sonneration alba

Pada stasiun III jenis yang ada di sana hampir sama dengan yang ada distasiun II, yaitu zona pertama didominasi oleh asosiasi famili Rhizophoraceae (R. apiculata, $R$. mucronata, Cerips tagal, Bruguiera gymnorhiza) dan Avicennia alba. Dari ketiga stasiun famili Rhizophoraceae paling banyak mendominasi dari jenis lainnya. Sehingga terlihat pada zonasi jenis - jenis Rhizophora Spp lebih tebal, baik dalam jumlah dan kerapatannya. 
Nilai Manfaat Langsung (Direct Use Value)

Nilai manfaat langsung merupakan nilai yang didapatkan oleh masyarakat akibat interaksi langsung terhadap suatu sumberdaya alam guna pemenuhan akan kebutuhan dan sebagai mata pencaharian. Berdasarkan hasil identifikasi, secara garis besar, nilai manfaat langsung yang didapatkan oleh masyarakat terdiri atas nilai manfaat hasil hutan dan nilai manfaat perikanan yang terdiri atas nilai manfaat yaitu nilai manfaat kayu untuk konstruksi rumah, manfaat kayu untuk bangunan rumah, manfaat kayu bakar, manfaat kayu untuk patok pagar, nilai manfaat ikan, nilai manfaat udang, dan nilai manfaat kepiting. Berdasarkan pemanfaatan langsung ekosistem hutan mangrove di Desa Dudepo, total nilai manfaat langsung dapat dikuantifikasi sebagai berikut :

Tabel 1. Kuantifikasi nilai manfaat langsung ekosistem hutan mangrove

\begin{tabular}{|c|c|c|c|}
\hline No & $\begin{array}{c}\text { Jenis Manfaat } \\
\text { Langsung }\end{array}$ & $\begin{array}{c}\text { Nilai Manfaat } \\
\text { bersih } \\
\text { (Rp/tahun) }\end{array}$ & $\begin{array}{c}\text { Persentase } \\
(\%)\end{array}$ \\
\hline 1. & $\begin{array}{l}\text { Kayu Untuk } \\
\text { Konstruksi } \\
\text { Rumah }\end{array}$ & 80.910 .000 & 9.84 \\
\hline 2. & $\begin{array}{l}\text { Kayu Untuk } \\
\text { Bangunan } \\
\text { Rumah }\end{array}$ & 121.400 .000 & 14.77 \\
\hline 3. & $\begin{array}{l}\text { Kayu Untuk } \\
\text { Patok dan } \\
\text { Pagar }\end{array}$ & 2.755 .000 & 0.34 \\
\hline 4. & $\begin{array}{l}\text { Kayu Untuk } \\
\text { Kayu Bakar }\end{array}$ & 29.820 .000 & 3.63 \\
\hline 5 & Ikan & 488.160 .000 & 59.37 \\
\hline 6 & Kepiting & 72.480 .000 & 8.82 \\
\hline 7 & Udang & 26.640 .000 & 3.24 \\
\hline & JUMLAH & 822.165 .000 & 100 \\
\hline
\end{tabular}

\section{Nilai Manfaat Tidak Langsung} (Indirect Use Value)

Manfaat tidak langsung adalah manfaat yang dirasakan secara tidak langsung terhadap barang dan jasa yang dihasilkan oleh sumberdaya dan lingkungannya. Berdasarkan hasil identifikasi terhadap keberadaan ekosistem hutan mangrove di Desa Dudepo, nilai manfaat tidak langsung yaitu nilai manfaat penahan abrasi dan erosi. Nilai Manfaat Penahan Abrasi dan Erosi Panjang pesisir pantai di Desa Dudepo yang ditumbuhi mangrove berdasarkan hasil tracking menggunakan GPS adalah \pm 320,2 meter. Manfaat tidak langsung manfaat tidak langsung dari hutan mangrove sebagai penahan abrasi disetimasi melalui replacement cost dengan pembangunan bangunan pemecah gelombang (break water). Menurut data Dinas Pekerjaan Umum Propinsi Sulawesi Utara (2012) untuk membuat bangunan pemecah gelombang dengan ukuran $37,5 \mathrm{~m} \times 2 \mathrm{~m} \times 2,5 \mathrm{~m}(\mathrm{p} \times 1 \times \mathrm{t})$ dengan daya tahan 5 tahun diperlukan biaya sebesar $\mathrm{Rp}$ 265.727.775 atau sekitar Rp. 7.086.074 per meter. Panjang garis pantai yang dilindungi hutan mangrove yaitu 320.2 meter. Nilai dari biaya pembuatan breakwater tersebut kemudian dikalikan dengan panjang garis pantai yang terlindungi hutan mangrove, yaitu sepanjang 320.2 meter. Hal ini dikarenakan bangunan pemecah ombak tersebut sudah dapat menggantikan fungsi dari hutan mangrove sebagai pemecah gelombang pada sepanjang garis pantai Desa Dudepo, sehingga manfaat tidak langsung mangrove sebagai penahan abrasi adalah sebesar Rp 2,268,960,894.80 Nilai tersebut kemudian dibagi 5 guna mendapatkan nilai per tahunnya. Dengan demikian manfaatnya adalah sebesar Rp. $453,792,178.96$ per tahun.

\section{Nilai Manfaat Pilihan (Option Value)}

Menurut (Fitriani, 2012) manfaat pilihan untuk hutan mangrove biasanya menggunakan metode benefit transfer yaitu metode pendekatan pemindahan asas manfaat dari tempat lain (dimana sumberdaya tersedia) lalu benefit tersebut ditransfer untuk memperoleh perkiraan yang kasar mengenai manfaat dari lingkungan. Nilai manfaat pilihan diestimasi dengan mengacu pada nilai keanekaragaman hayati (biodiversity) hutan mangrove di Indonesia yaitu US\$ $1.500 / \mathrm{km} /$ tahun atau US\$ 15/ha/tahun (Ruittenbeek, 1992) dalam (Maedar, 2008). Total luas hutan mangrove di Desa Dudepo mencapai 15 ha. Bila dikalikan dengan nilai keanekaragaman hayati (biodiversity) hutan mangrove di Indonesia US\$ 15/ha/tahun, maka nilai manfaat pilihan ekosistem hutan mangrove di Desa Dudepo mencapai US\$22,500 bila dikonversi ke nilai rupiah, dengan kurs sebesar Rp. 13.618 (27 Oktober 2017) maka total nilai 
manfaat pilihan ekosistem hutan mangrove di Desa Dudepo sebesar Rp. 306.405.000/tahun.

\section{Nilai Manfaat Eksistensi (Eksistence Value)}

Nilai manfaat eksistensi dihitung berdasarkan pendekatan metode Contingen value method/CVM atau metode survey. Survey dilakukan untuk mengetahui keinginan masyarakat membayar (willingness to pay/WTP) atas keberadaan dan setiap manfaat yang diperoleh dari ekosistem hutan mangrove. Berdasarkan hasil survey yang dilakukan terhadap responden yang berjumlah 39 orang, dimana tingkat pendidikan dan umur responden menjadi tolak ukur utama dalam penilaian, diperoleh hasil penilaian yang bervariasi. Berikut adalah Tabel 2. Persentase nilai manfaat eksistensi berdasarkan umur dan pendidikan.

Berdasarkan data pada Tabel 2. Terlihat bahwa pada umur produktif (15 s/d 54 tahun) dan tidak produktif ( $0 \mathrm{~s} / \mathrm{d} 14$ tahun dan 55 tahun keatas) memiliki perbedaan dalam menilai manfaat eksistensi atau keberadaan hutan mangrove di sekitar desa mereka. Pada umur produktif, masyarakat biasanya memiliki kemampuan lebih banyak untuk bekerja sehingga hasil dan manfaat yang diperoleh dari keberadaan hutan mangrove di sekitar kampung mereka juga lebih banyak. Berbeda dengan mereka yang tidak produktif, kemampuan mereka lebih terbatas sehingga hasil dan manfaat yang diperoleh pun terbatas. Sehingga dapat disimpulkan bahwa semakin produktif seseorang maka akan semakin besar manfaat yang diperoleh dari keberadan ekosistem hutan mangrove sehingga berdampak pula pada besarnya penilaian mereka terhadap ekosistem hutan mangrove tersebut.

Berdasarkan hasil survey, rata-rata nilai manfaat eksistensi hutan mangrove masyarakat Desa Dudepo sebesar Rp. 890.244/ha/tahun. Jika luas hutan mangrove di Desa Dudepo sebesar 15 ha, maka total nilai manfaat eksistensi hutan mangrove di Desa Dudepo adalah sebesar 13.353.660, /tahun dapat dilihat pada Tabel 3 .

\section{Nilai Manfaat Warisan (Bequest Value)}

Ekosistem mangrove sebagai warisan yang mempunyai nilai yang sangat tinggi.Nilai manfaat warisan ekosistem mangrove yang dimiliki tidak dapat dinilai dengan pendekatan nilai pasar. Oleh karena itu, nilai warisan dapat dihitung dengan pendekatan perkiraan dengan nilai warisan tidak kurang $10 \%$ dari nilai manfaat langsung hutan mangrove (Ruitenbeek, 1991) dalam (Marhayana, 2012). Sehubungan dengan telah diketahuinya total nilai manfaat langsung dari ekosistem hutan mangrove di Desa Dudepo, maka perkiraan nilai warisan ekosistem hutan mangrove di Desa Dudepo adalah Rp. 822.165.000/tahun x $10 \%=$ 82.216.500,/tahun.

\section{Nilai Ekonomi Total Ekosistem Hutan Mangrove di Desa Dudepo}

Berdasarkan hasil identifikasi terhadap seluruh nilai manfaat ekosistem hutan mangrove di Desa Dudepo yang terdiri atas manfaat langsung, manfaat tidak langsung, manfaat pilihan, manfaat eksistensi dan manfaat warisan yang kemudian mengkuantifikasi nilai tersebut kedalam nilai rupiah, maka diperoleh Nilai Ekonomi Total dari keseluruhan manfaat tersebut dapat dilihat pada Tabel 4.

Proporsi dari Nilai Ekonomi Total ekosistem hutan mangrove di Desa Dudepo dapat dilihat pada Gambar 2.

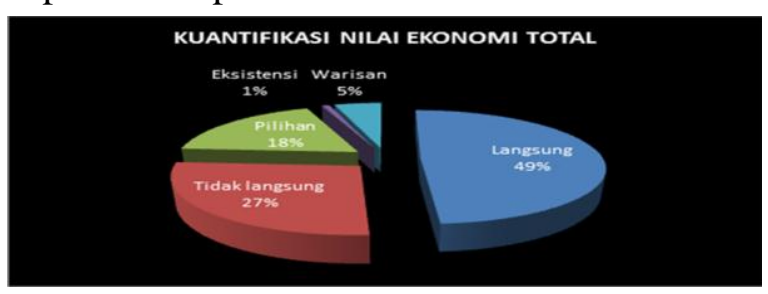

Gambar 2. Proporsi Nilai Ekonomi Total ekosistem hutan mangrove di Desa Dudepo.

Berdasarkan gambar diatas, memperlihatkan bahwa manfaat tidak langsung ekosistem hutan mangrove di Desa Dudepo memiliki peranan yang sangat penting. Hal ini sesuai dengan pendapat dari responden yang dijumpai, bahwa keberadaan ekosistem hutan mangrove di Desa Dudepo memberikan dampak positif terhadap kehidupan mereka. Salah satu dampak positif yang dirasakan masyarakat adalah persediaan ikan yang cukup melimpah. Sebagaimana diketahui bahwa salah satu manfaat dari ekosistem hutan mangrove adalah sebagai tempat mencari makan dan berlindung beberapa jenis ikan dan hewan-hewan laut lainnya. Hal inilah yang membuat masyarakat berupaya untuk menjaga dan mempertahan- 
kan kondisi ekosistem hutan mangrove agar tidak mengalami kerusakan. Dampak positif lain yang dirasakan masyarakat adalah adanya rasa nyaman dan hawa udara yang sejuk karena hutan mangrove mampu menyerap karbon dan penghasil oksigen yang sangat berguna bagi peningkatan kualitas lingkungan hidup.

Proporsi nilai ekonomi total berikutnya adalah manfaat langsung dan manfaat eksistensi. Selama ini masyarakat Desa Dudepo memanfaatkan sumberdaya alam yang terdapat didalam dan sekitar hutan mangrove secara terbatas, hal ini bisa dilihat dengan kondisi masyarakat yang cukup tradisional dengan sumberdaya yang terbatas dan sistem peralatan yang sederhana. Bila melihat persentase nilai manfaat langsung dan manfaat eksistensi pada gambar 8, terdapat selisih jauh berbeda karena masyarakat berpendapat bahwa manfaat langsung yang dirasakan masyarakat tidak sebanding dengan eksistensinya atau keberadaanya. Penghargaan masyarakat terhadap keberadaan suatu sumberdaya alam tidak sebanding dengan nilai ekonomi dari manfaat langsung yang diperoleh. Jika nilai manfaat langsung yang diterima masyarakat besar maka dipastikan akan berbanding lurus dengan nilai eksistensinya, namun bila nilai manfaat langsung terus meningkat maka akan menurunkan nilai manfaat tidak langsungnya. Apabila terjadi pemanfaatan yang besarbesaran, nantinya akan terjadi tekanan terhadap sumberdaya alam mangrove sekitar dan apabila hal ini terus berlanjut, maka lambat laun sumberdaya alam mangrove akan terkikis dan hilang. Pada akhirnya, manfaat langsung pun akan habis bersamaan dengan hilangnya sumberdaya alam tersebut.

Proporsi selanjutnya adalah manfaat pilihan dengan persentase $18 \%$. Ekosistem hutan mangrove sebagai suatu keanekaragaman hayati (biodiversity) yang dinilai sebesar US\$ 15/ha/tahun, dengan luas hutan mangrove di Desa Dudepo 15 ha, ternyata cukup kecil. Hal ini mungkin akan berbeda jika nilai suatu keanekaragaman hayati hutan mangrove lebih besar dari nilai yang telah ditetapkan sebelumnya. Walaupun nilai pilihan ekosistem hutan mangrove di Desa Dudepo cukup kecil, namun hutan mangrove di Desa Dudepo sebagai suatu keanekaragaman hayati memiliki banyak potensi yang belum diketahui seluruhnya. Proporsi terakhir ditempati oleh nilai warisan. Nilai yang diwariskan dari sumberdaya alam sangat tergatung dari seberapa besar manfaat langsung yang dirasakan masyarakat. Semakin besar manfaat langsung yang dirasakan masyarakat maka akan semakin besar pula nilai yang diwariskan kepada anak cucunya kelak.

\begin{tabular}{|c|c|c|c|c|c|c|c|c|}
\hline \multirow[b]{2}{*}{$\begin{array}{c}\text { Umur } \\
\text { (Tahun) }\end{array}$} & \multicolumn{8}{|c|}{ Nilai Manfaat Eksistensi (Rp/ha/tahun) } \\
\hline & $\begin{array}{c}250.000 \\
500.000\end{array}$ & $\%$ & $\begin{array}{l}500.000- \\
750.000\end{array}$ & $\%$ & $\begin{array}{l}750.000-0^{-1.000 .000} \\
\end{array}$ & $\%$ & Jml & $\%$ \\
\hline Produktif & 27 & 81,81 & 4 & 80 & 1 & 100 & 32 & 82,05 \\
\hline $\begin{array}{l}\text { Tidak } \\
\text { Produktif }\end{array}$ & 6 & 18,18 & 1 & 20 & & & 7 & 17,49 \\
\hline Jumlah & 33 & 100 & 5 & 100 & 1 & 100 & 39 & 100 \\
\hline
\end{tabular}

Tabel 3. Persentase nilai manfaat eksistensi berdasarkan umur

\begin{tabular}{|c|c|c|c|c|c|c|c|c|}
\hline \multirow{2}{*}{$\begin{array}{c}\text { Umur } \\
\text { (Tahun) }\end{array}$} & \multicolumn{8}{|c|}{ Nilai Manfaat Eksistensi (Rp/ha/tahun) } \\
\hline & $\begin{array}{l}250.000 \\
-500.000\end{array}$ & $\%$ & $\begin{array}{l}500.000-0 \\
750.000\end{array}$ & $\%$ & $\begin{array}{l}750.000- \\
1.000 .000\end{array}$ & $\%$ & Jml & $\%$ \\
\hline SD & 22 & 70,96 & 9 & 69,23 & 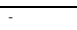 & $=$ & 31 & 79,49 \\
\hline SMP & 3 & 9,67 & 1 & 7,69 & . & - & 4 & 10,25 \\
\hline SMA & 2 & $\begin{array}{l}6.9 \\
45\end{array}$ & 1 & 7,69 & 1 & 33,33 & 4 & 10,25 \\
\hline Jumlah & 31 & 100 & 13 & 100 & 3 & 100 & 39 & 100 \\
\hline
\end{tabular}

Tabel 4. Kuantifikasi Nilai Ekonomi Total ekosistem hutan mangrove di Desa Dudepo

\begin{tabular}{clcc}
\hline No & Jenis Manfaat & $\begin{array}{c}\text { Nilai Manfaat } \\
\text { (Rp/tahun) }\end{array}$ & Persentase (\%) \\
\hline 1. & Langsung & 822.165 .000 & 49,00 \\
2. & Tidak langsung & 453.792 .178 & 27,04 \\
3. & Pilihan & 306.405 .000 & 18,26 \\
4. & Eksistensi & 13.353 .660 & 0,80 \\
5. & Warisan & 82.216 .500 & 4,90 \\
\hline & JUMLAH & 1.677 .932 .338 & 100 \\
\hline
\end{tabular}

\section{KESIMPULAN DAN SARAN}

\section{Kesimpulan}

Berdasarkan penelitian yang dilakukan di Desa Dudepo Kecamatan Bolaang Uki Kabupaten Bolaang Mongondow Selatan, dapat disimpulkan sebagai berikut : 
1. Hasil identifikasi terhadap berbagai jenis manfaat yang diperoleh masyarakat Desa Dudepo terhadap ekosistem hutan mangrove terdiri atas manfaat nilai manfaat langsung yang didapatkan oleh masyarakat terdiri atas nilai manfaat hasil hutan dan nilai manfaat perikanan (manfaat kayu untuk konstruksi rumah, manfaat kayu untuk bangunan rumah, manfaat kayu bakar, manfaat kayu untuk patok dan pagar, manfaat ikan, manfaat udang, dan manfaat kepiting). Manfaat tidak langsung manfaat penahan abrasi dan erosi, manfaat pilihan, manfaat eksistensi dan manfaat warisan.

2. Nilai ekonomi total ekosistem hutan mangrove di Desa Dudepo terdiri atas nilai manfaat langsung sebesar $\mathrm{Rp}$. 822.165.000/tahun nilai manfaat tidak langsung sebesar Rp. 453.792.178/tahun, nilai manfaat pilihan sebesar $\mathrm{Rp}$. 306.405.000./tahun, nilai manfaat eksistensi sebesar Rp. 1.372.635/tahun, nilai manfaat eksistensi sebesar Rp. 13.353.660/tahun. dan nilai manfaat warisan sebesar Rp. 82.216.500/tahun. Jumlah nilai ekonomi total keseluruhan manfaat ekosistem hutan mangrove di Desa Dudepo adalah sebesar Rp. 1.677.932.338./tahun.

3. Nilai manfaat yang di hasilkan oleh ekonomi total ekosistem hutan mangrove di Desa Dudepo yang dihasilkan dapat saja berubah tergantung pada pemanfaatannya oleh masyarakat setempat dimasa yang akan datang.

\section{Saran}

1. Bila melihat besarnya nilai ekonomi total ekosistem hutan mangrove di Desa Dudepo yang diperoleh masyarakat setempat, sudah semestinya masyarakat tetap menjaga kelestarian sumberdaya alam tersebut sehingga masyarakat akan tetap mendapatkan manfaat langsung dan tidak langsung dari keberadaan ekosistem hutan mangrove tersebut.
2. Perlu adanya pengelolaan yang baik terhadap masyarakat dan ekosistem mangrove itu sendiri agar masyarakat tidak terlalu mengeksploitasi hutan mangrove secara besar-besaran dan kondisi hutan mangrove tetap terjaga baik.

3. Dalam perencanaan wilayah hutang mangrove di tanjung dudepo seharusnya memperhitungkan nilai ekonomisekologis ekosistem hutan mangrove, mengingat besarnya potensi ekonomi ekositem hutan mangrove yang besar, jika dimanfaatkan dengan baik akan memberikan manfaat yang lebih maksimal bagi masyarakat.

4. Diperlukan pengelolaan mangrove yang meliputi aspek perlindungan dan konservasi sehingga ketersediaan sumberdaya hutan mangrove tetap lestari dan terjamin serta adanya penerapan peraturan tentang pentingnya menjaga kelestarian ekosistem mangrove, dengan pengawasan yang ketat baik oleh pihak pengelola maupun dengan partisipasi masyarakat setempat.

\section{DAFTAR PUSTAKA}

Anonimous, 2009 Kronologis Kawasan Hutan Propinsi Sulawesi Utara. Pemerintah Propinsi Sulawesi Utara. Manado Rencana Tata Ruang Wilayah Kabupaten Bolaang Mongondow Selatan. Pemerintah Kabupaten Bolaang Mongondow Selatan. Molibagu.

Azis, N. 2006. Analisa Ekonomi Alternatif Pengelolaan Ekosistem Mangrove Kecamatan Barru Kabupaten Baru. Tesis Pascasarjana Program Studi Ekonomi Sumberdaya Kelautan Tropika, Institut Pertanian Bogor, Bogor. 
Baderan, D. 2013. Model Valuasi Ekonomi Sebagai Dasar Untuk Rehabilitasi Kerusakan Hutan Mangrove di Wilayah Pesisir Kecamatan Kwandang Kabupaten Gorontalo Utara. UGM Press. Yogyakarta.

Begen, D.G. 2006. Pedoman Teknis Pengenalan dan Pengelolaan Ekosistem Mangrove. Penerbit Pusat Kajian Sumber Daya Pesisir dan Lautan, IPB

Budiman, A. dan Suharjono. 2004. Penelitian Hutan Mangrove di Indonesia : Pendayagunaan dan Konservasi. Prosiding Lokakarya Nasional Penyusunan Program Penelitian Kelautan.

Departemen Kehutanan. 2006. Konsep Nilai Ekonomi Total dan Metode Penilaian Sumberdaya Hutan. http://www. litbang. dephut. go. id/ file (3 Oktober Juli 2017).

Fitriani. 2012. Estimasi Manfaat Ekonomi Ekosistem Mangrove Telaga Wasti Kabupaten Manokwari. Skripsi Sarjana Program Studi Kehutanan, Fakultas Kehutanan, Universitas Negeri Papua, Manokwari.

Ghufron, H. 2012. Ekosistem Mangrove: Potensi, Fungsi, dan Pengelolaan. Rineka Cipta. Jakarta.

Harahap, N. 2010. Penilaian Ekonomi Ekosistem Hutan Mangrove dan Aplikasinya dalam Perencanaan Wilayah Pesisir, Graha Ilmu, Yogyakarta.

Ramadhan, A. 2010. Penilaian Ekonomi Hutan Mangrove dengan Study Kasus Desa Pantai Bahagia, Kecamatan Muara Gembong, Kabupaten Bekasi, Jawa Barat. Skripsi. Fakultas Ekonomi dan
Irmadi, 2004. Konsep Valuasi Ekonomi Sumberdaya Alam. valuasi ekonomi sumberdaya alam.

Kementerian Kehutanan RI, 2013. Pedoman Harga Satuan Pokok Kegiatan (HSPK) Bina Pengelolaan Daerah Aliran Sungai tahun 2013. Jakarta : Kementerian Kehutanan RI.

Kustanti, A. 2011. Manajemen Hutan Mangrove. Institut Pertanian Bogor. Bogor.

Maedar, F. 2008. Analisis Ekonomi Pengelolaan Mangrovedi Kecamatan Merawang Kabupaten Bangka. Tesis Pascasarjana Program Studi Ekonomi Sumberdaya Kelautan Tropika, Institut Pertanian Bogor.

Marhayana, S., Niartiningsih, A., Idrus, R. 2012. Manfaat Ekonomi Ekosistem Mangrove di Taman Wisata Perairan Padaido Kabupaten Biak Numfor, Papua. Fakultas Ilmu Kelautan dan Perikanan Universitas Hasanuddin, Makassar.

Noor, Y. R., Khazali, M., Suryadiputra, I. N. N. 1999. Panduan Pengenalan Mangrove di Indonesia. PKA/WI-IP, Bogor.

Nugroho, T. S. 2009. Kajian Pengelolaan Ekosistem Mangrove Pada Kawasan Hutan Lindung di Desa Dabong, Kecamatan Kubu, Kabupaten Kubu Raya, Kalimatan Barat. Tesis Pascasarjana Program Studi Pengelolaan Sumber daya Pesisir dan Lautan, Institut Pertanian Bogor.

Manajemen Institut Pertanian Bogor.

Rignolda, 2010.Laporan : Survei Potensi Hutan Mangrove di Kabupaten Bolaang Mongondow Selatan. Manado. 
Pramuji, 2000 Hutan Mangrove di Indonesia : Wantasen, A. 2000. Kajian Potensi Peranan permasalahan dan Sumberdaya Hutan Mangrove di Pengelolaannya. Osena (Majalah Desa Talise Kabupaten Minahasa, Ilmiah Semi Populer Vol. XXV Sulawesi Utara. Makalah Falsafah No.1) LIPI Pusat Penelitian dan Sains. Program Pasca Sarjana. Pengembangan Oseannologi. Jakarta. Institut Pertanian Bogor.

41 Hal. 